\title{
Virtual reality in stroke rehabilitation: virtual results or real values?
}

\author{
Realidade virtual na reabilitação de AVC: resultados virtuais ou valores reais? \\ Marco IOSA'
}

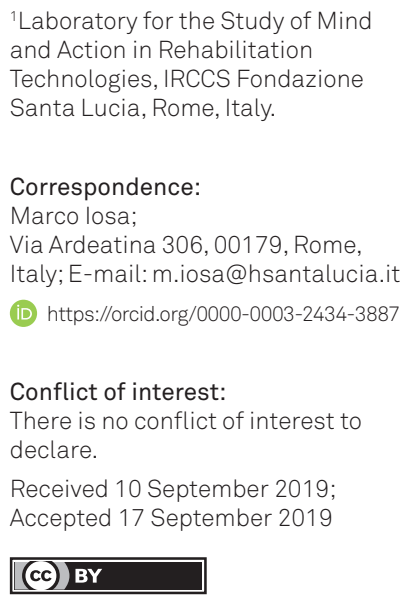

${ }^{1}$ Laboratory for the Study of Mind and Action in Rehabilitation Technologies, IRCCS Fondazione Santa Lucia, Rome, Italy.

\section{Correspondence:}

Marco losa;

Via Ardeatina 306, 00179, Rome, Italy; E-mail:m.iosa@hsantalucia.it

(iD) https://orcid.org/0000-0003-2434-3887

Conflict of interest:

There is no conflict of interest to declare.

Received 10 September 2019 ; Accepted 17 September 2019

\section{(c) BY}

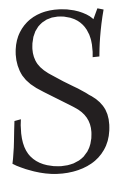

even Capital Devices for the Future of Stroke Rehabilitation was the title of a review published seven years ago by our group, in which we analyzed the most promising technologies for neurorehabilitation ${ }^{1}$. They were: robots, virtual reality, brain computer interfaces, wearable devices for human movement analysis, noninvasive brain stimulators (such as transcranial direct current stimulation and transcranial magnetic stimulation), neuroprostheses, and computers/tablets for electronic clinical records and planning ${ }^{1}$.

Seven years later, we can now take stock of the situation. We must be honest: on one hand, we can surely affirm that the above-proposed technologies have really been the most developed and applied in these last years, but on the other hand, we should say that questions about their efficacy are still open, as reported by Cochrane reviews highlighting the need of further studies ${ }^{2,3}$.

However, every month, new studies claiming the efficacy of technological rehabilitation are published, and this continuously-growing amount of literature reveals the lack of definitive proof; otherwise all these studies would have been unnecessary. This "efficacy paradox" could potentially give us many more years of research without any conclusive results, especially because the more technology is adaptable to the needs of the patients (as clinicians want), the less the protocol to test the efficacy of that technology is standardizable (as researchers want $)^{4}$.

Furthermore, the pressure on researchers to publish, the optimism about the use of technologies of some clinicians, the hopes of patients and their caregivers about new miraculous approaches, and the commercial interests of technology companies, may lead to some misleading claims in the mass media. For example, in many scientific and journalistic papers, some electromechanical devices without any intelligence on board are improperly called "robots", nonimmersive video games are called "virtual reality", the expressions "mind power" or "force of thought" are associated with brain computer interfaces ${ }^{1}$. Market analysts expect that the greatest developing field for robots in the next five years will be rehabilitation, compared with other fields ${ }^{5}$. Conversely, computers, the Internet and smartphones have changed our lives and were not directly developed for rehabilitation, but this clinical field may benefit from all the developed know-how. Virtual reality should be differentiated by video games, referring to a high-end user-computer interface involving real-time stimulation based on the three "I's": immersive experience, interaction, and imagination'.

In this scenario, the recent study by Ogun and colleagues clearly shows all the potentials of using a Leap Motion controller interfaced with 3D immersive virtual reality to improve the upper extremity functions in patients with ischemic stroke $e^{7}$. The Leap Motion controller is an optical tracking system including three infrared light emitters and two infrared cameras for tracking hand and finger kinematics, interfacing them with a virtual environment developed as a human-computer interface. In 2014, our group published the first feasibility pilot study proposing the use of Leap Motion in neurorehabilitation, noting its advantageous features: it is precise, markerless, low-cost, small, and easy to use ${ }^{8}$.

Ogun and colleagues have confirmed our intuition: they found that virtual reality rehabilitation guided by a Leap Motion controller appeared to be effective in improving upper 
extremity function and self-care skills (but not functional independence), more than conventional therapy, in a wide sample of patients ${ }^{7}$.

Many studies have reported that the sense of presence, of body ownership and agency elicited by virtual reality are similar to those in the real environment, and daily life activities have been replicated in virtual environments for training patients. But what is the real value of virtual reality in rehabilitation if it is just a replication of a real environment? Virtual reality can also elicit amusement, arousal and valence, even more than in the real environment, as happens in virtual reality-based video games. Amusement can improve participation, arousal can improve brain activities, valence can improve learning 9 . It seems to be time for a generation of amusing and immersive virtual reality for improving real outcomes in neurorehabilitation.

\section{References}

1. Iosa M, Morone G, Fusco A, Bragoni M, Coiro P, Multari M, et al. Seven capital devices for the future of stroke rehabilitation. Stroke Res Treat. 2012;2012:187965. https://doi.org/10.1155/2012/187965

2. MehrholzJ, Pohl M, Platz T, Kugler J, Elsner B. Electromechanical and robotassisted arm training for improving activities of daily living, arm function, and arm muscle strength after stroke. Cochrane Database Syst Rev. 2018 Sep;9:CD006876. https://doi.org/10.1002/14651858.CD006876.pub5

3. Laver KE, Lange B, George S, Deutsch JE, Saposnik G, Crotty M. Virtual reality for stroke rehabilitation. Cochrane Database Syst Rev. 2017 Nov;11:CD008349. https://doi.org/10.1002/14651858.CD008349.pub4

4. Iosa M, Morone G, Cherubini A, Paolucci S. The Three laws of neurorobotics: a review on what neurorehabilitation robots should do for patients and clinicians. J Med Biol Eng. 2016;36(1):1-11. https://doi.org/10.1007/s40846-016-0115-2

5. Ugalmugale $\mathrm{S}, \mathrm{Mupid} \mathrm{S}$. Healthcare assistive robot market size by product. City: Global Market Insights, 2017.
6. Burdea GC, Coiffet P. Virtual reality technology. 2nd ed. Hoboken, NJ: John Wiley \& Sons; 2003.

7. Ögün1 MN, Kurul R, Yașar MF, Turkoglu SA, Avcı S, Yildiz N. Effect of leap motion-based 3D immersive virtual reality usage on upper extremity function in ischemic stroke patients. Arq Neuropsiquiatr 2019;77(10):681-88. https://doi.org/10.1590/0004-282X20190129

8. Iosa M, Morone G, Fusco A, Castagnoli M, Fusco FR, Pratesi L, et al. Leap motion controlled videogame-based therapy for rehabilitation of elderly patients with subacute stroke: a feasibility pilot study. Top Stroke Rehabil. 2015 Aug;22(4):306-16. https://doi.org/10.1179/1074935714Z.0000000036

9. Tieri G, Morone G, Paolucci S, Iosa M. Virtual reality in cognitive and motor rehabilitation: facts, fiction and fallacies. Expert Rev Med Devices. 2018 Feb;15(2):107-17. https://doi.org/10.1080/17434440.2018.1425613 